\title{
Primary Extranodal Non-Hodgkin Lymphoma of the Head and Neck in Patients with Acquired Immunodeficiency Syndrome: A Clinicopathologic Study of 24 Patients in a Single Hospital of Infectious Diseases in Argentina
}

\author{
Marcelo Corti ${ }^{1,2}$ María Villafañe ${ }^{1} \quad$ Alicia Bistmans $^{3}$ \\ ${ }^{1}$ Department of HIV/AIDS, Infectious Diseases F. J. Muñiz Hospital, \\ Buenos Aires, Argentina \\ 2 Department of Internal Medicine, University of Buenos Aires School \\ of Medicine, Paraguay, Buenos Aires, Argentina \\ ${ }^{3}$ Department of Oncology, Ramos Mejía Hospital, Buenos Aires, Argentina \\ ${ }^{4}$ Department of Histopathology, National Academy of Medicine, \\ Buenos Aires, Argentina \\ ${ }^{5}$ Department of Scientific Coordinator, Sociedad Iberoamericana de \\ Información Científica, Buenos Aires, Argentina
}

Int Arch Otorhinolaryngol 2014;18:260-265.
Marina Narbaitz ${ }^{4}$ Leonardo Gilardi ${ }^{5}$

\begin{abstract}
Address for correspondence Prof. Marcelo Corti, MD, Department of HIV/AIDS, Infectious Diseases F. J. Muñiz Hospital, Puán 381, 2 floor, Buenos Aires, C1406CQG, Argentina (e-mail: marcelocorti@fibertel.com.ar).
\end{abstract}

\begin{abstract}
Keywords

- non-Hodgkin lymphoma

- head and neck

- AIDS

- HIV

Introduction Extranodal non-Hodgkin lymphomas (NHLs) are commonly described in patients with acquired immunodeficiency syndrome (AIDS) and are related with an atypical morphology and aggressive clinical course. AIDS-associated lymphomas are characterized by their rapid progression, frequent extranodal manifestations, and poor outcome.

Objective The aim of this article is to remake the clinical features of head and neck (HN) NHL in patients with AIDS to facilitate early diagnosis and treatment.

Methods We evaluated the epidemiologic, clinical, immunologic, virologic, and histopathologic characteristics of 24 patients with human immunodeficiency virus (HIV)/AIDS with primary HN NHL treated at a single institution between 2002 and 2012. Histopathologic diagnosis was made according to the criteria of the World Health Organization Classification of Tumors of Hematopoietic and Lymphoid Tissues. Additional immunohistochemical stains were applied in all cases.

Results Eighteen patients (75\%) were men and the median of age was 39 years. The gingiva and the hard palate were the most common sites of the lesions (15 patients, $62.5 \%$ ). Lactate dehydrogenase levels were elevated in 16 cases (84\%). Bone marrow infiltration was detected only in 4 cases (16.6\%). The median CD4 T-cell count was 100 cells/ $\mu \mathrm{L}$. According to the histopathologic evaluation, the most common subtype was diffuse large B-cell lymphoma (12 cases, 50\%), followed by plasmablastic lymphoma ( 9 cases, $37.5 \%$ ) and Burkitt lymphoma (3 cases, $12.5 \%$ ).

Conclusion $\mathrm{HN} \mathrm{NHL}$ is a severe complication of advanced HIV/AIDS disease. Early diagnosis followed by chemotherapy plus highly active antiretroviral treatment is necessary to improve the prognosis and the survival of these patients.
\end{abstract}

received

October 29, 2013

accepted

March 1, 2014

published online

April 9, 2014
DOI http://dx.doi.org/

10.1055/s-0034-1373782. ISSN 1809-9777.
Copyright $(2014$ by Thieme Publicações License terms

Ltda, Rio de Janeiro, Brazil
(요 (1) $\Theta \circledast$ 


\section{Introduction}

Non-Hodgkin lymphoma (NHL) is an acquired immunodeficiency syndrome (AIDS)-defining neoplasm that is mostly a high-grade B-cell lymphoma. In patients with AIDS, NHL represents the second most common malignancy after Kaposi sarcoma. Patients with human immunodeficiency virus (HIV) infection are at increased risk to develop NHL. ${ }^{1,2}$ HIV infection increases the risk to develop NHL 100 to 200 times higher than in the general population. ${ }^{2}$ These lymphomas are characterized by their rapid progression, frequent extranodal initial manifestations, and poor outcome. ${ }^{2}$ This characteristic of extranodal involvement as the clinical presentation of the disease is common to all subtypes of AIDS-related lymphomas, including diffuse large B-cell lymphoma (DLBCL), Burkitt lymphoma (BL), and plasmablastic lymphoma (PBL). ${ }^{3}$ Extranodal head and neck (HN) NHL comprises a group of various tumors with different histology, treatment, and prognosis.

Although the widespread use of highly active antiretroviral treatment has been associated with a significant decrease of some opportunistic infections and Kaposi sarcoma, this is not as clear in the case of NHL and Hodgkin lymphoma in HIVseropositive patients.

The present study is a retrospective evaluation of patients with primary extranodal HN NHL treated at a reference Infectious Diseases Hospital in Buenos Aires, Argentina.

\section{Methods}

A retrospective study was performed of 24 patients with AIDS and extranodal HN NHL assisted at a single hospital in Argentina between 2002 and 2012. We revised retrospectively the epidemiologic, clinical, histopathologic, immunologic, and virologic findings and the outcome. The patients were clinically staged according to the Ann Arbor system and the American Joint Committee on Cancer (AJCC). ${ }^{4}$ All diagnoses were confirmed by the histopathologic examination of biopsy smears obtained from the lesions. We examined all patients and obtained complete blood cell counts, serum biochemistry including lactate dehydrogenase ( $\mathrm{LDH}$ ) levels, and hepatitis $\mathrm{B}$ and $\mathrm{C}(\mathrm{HCV})$ serology for all patients. To define the neoplasm extension, we performed bone marrow aspirate, trephine biopsy, and chest X-ray and complete tomography scan of the head and neck region, brain, thorax, abdomen, and pelvis. Histopathologic diagnosis was made according to the criteria of the World Health Organization (WHO) Classification of Tumors of Hematopoietic and Lymphoid Tissues. ${ }^{5}$ Additional immunohistochemical stains were applied in all cases. Immunohistochemistry examination included analysis of $K_{i} 67$ (proliferative) index and the mouse monoclonal antibodies directed against CD20, CD45, CD10, CD138, plasma cell clone VS38c, and BCL-6. The primary antibodies were from DAKO Diagnostics, Copenhagen, Denmark.

Epstein-Barr virus (EBV)-associated latent membrane protein-1 detected by immunohistochemical and EBV-encoded mRNAs (EBERs) by in situ hybridization were analyzed in biopsy smears. Based on the correct histopathologic setting, a cutoff of $10 \%$ was adopted to consider EBER as positive. Detection of human herpesvirus-8 (HHV-8) RNA was performed by reverse transcriptase polymerase chain reaction only in those patients with oral cavity involvement.

All available data were analyzed with Microsoft Office Excel 2003 (Microsoft Corp., Redmond, WA). Continuous variables were compared using Student test and the association levels were analyzed with chi-square or Fisher exact tests. A $p$ value $<0.05$ was considered to be statistically significant.

\section{Results}

During the 10-year period, 106 HIV-infected patients were diagnosed with lymphomas; 73 (69\%) of them were NHL and 33 (31\%) were Hodgkin disease. Twenty-four of the NHLs (32.8\%) were diagnosed as HN NHL and were included in this study; 18 (75\%) occurred in men and 11 (45.8\%) in intravenous drug abusers (IVDAs). At the time of the neoplasm diagnosis, the median of age was 39 years. No difference between mean age, sexual practice, or IVDA of the whole cohort of patients with lymphoma and HIV/AIDS and the type of HN NHL was noted.

Considering the AJCC and using the Ann Arbor Classification System, 8 patients were stage Ie, 9 patients were stage Ile, and the last 7 were stage IV ( - Table $\mathbf{1}$ ).

B symptoms, including fever, weight loss, and night sweats, were present in the majority of patients. No evidence of concomitant opportunistic infection was found in the microbiologic laboratory analysis.

LDH levels were available for 19 patients and were elevated in 16 (84\%). The median LDH level was $1,225 \mathrm{U} / \mathrm{L}$ (313 to 5,800 $\mathrm{U} / \mathrm{L}$ ). As our laboratory established $450 \mathrm{U} / \mathrm{L}$ as the upper normal reference value, we stratified the HN NHL cohort into quartiles. All patients with normal LDH levels were included in the first quartile (range: 0 to $478.5 \mathrm{U} / \mathrm{L}$ ). LDH level within the first quartile was associated with absence of bone marrow infiltration. After excluding an outlier patient with initial LDH level higher than 5,000 $\mathrm{U} / \mathrm{L}$, the range of the first quartile was set between 0 and 473.25 U/L. Again, normal LDH levels were correlated with absence of bone marrow infiltration. No correlation could be identified among LDH concentration and infiltration of skin or bone tissue, HCV serologic status, or survival rates.

Bone marrow infiltration was detected only in 4 patients (16.6\%, 3 cases of DLBCL and 1 case of PBL) and only 4 patients (16.6\%) presented regional nodal involvement, 2 with DLBCL and 2 with PBL. The 4 patients (16.6\%) with nodal compromise were HCV-negative, and the bone marrow biopsy was negative to atypical cells in all of them. Demographic findings are summarized in - Table $\mathbf{1}$.

The gingiva and the hard palate were the most common site of the lesions (15 patients, $62.5 \%$ ), followed by the bone including the upper and lower maxilla (6 cases, 26\%), the skin and soft tissue ( 5 cases, $21 \%$ ) that involved the gingiva and the palate, the parotid gland ( 3 cases, 13\%), and the tonsils (2 cases, $8 \%$ ). Some patients presented more than one tumor tissue infiltration. Localizations are described in - Table 2. 
Table 1 Demographic and clinical findings in head and neck non-Hodgkin lymphomas in patients with HIV $(n=24)$

\begin{tabular}{|l|l|l|l|l|l|l|}
\hline Patient no. & Gender & Age (y) & Risk factor & Neoplasm stage & Bone marrow infiltration & LDH level \\
\hline 1 & M & 52 & UHC & le & Negative & 1,422 \\
\hline 2 & M & 31 & Hemophilic & le & Negative & N/D \\
\hline 3 & M & 44 & IVDA & IVe & N/D & N/D \\
\hline 4 & M & 26 & IVDA & Ile & N/D & 843 \\
\hline 5 & M & 32 & IVDA & Ile & N/D & 950 \\
\hline 6 & M & 38 & IVDA & Ile & Negative & 1,375 \\
\hline 7 & M & 43 & IVDA & IVe & Positive & N/D \\
\hline 8 & M & 51 & NPHC & lle & Negative & N/D \\
\hline 9 & M & 37 & UHC & IVes & Positive & 1,265 \\
\hline 10 & M & 51 & IVDA & le & Negative & 1,433 \\
\hline 11 & F & 25 & UHC & Ile & Negative & 1,186 \\
\hline 12 & F & 24 & UHC & Ile & Negative & 489 \\
\hline 13 & M & 35 & UHC & le & Negative & 313 \\
\hline 14 & M & 38 & IVDA & IVe & N/D & 1,404 \\
\hline 15 & M & 47 & NPHC & IVe & Positive & 2,721 \\
\hline 16 & M & 39 & IVDA & IVe & Positive & 1,365 \\
\hline 17 & M & 43 & UHC & le & N/D & 460 \\
\hline 18 & F & 35 & UHC & le & N/D & 5,800 \\
\hline 19 & M & 29 & NPHC & lle & N/D & 468 \\
\hline 20 & M & 37 & UHC & Ile & N/D & 926 \\
\hline 21 & F & 60 & UHC & Ile & N/D & N/D \\
\hline 22 & F & 42 & IVDA & IVe & Negative & 348 \\
\hline 23 & M & 39 & IVDA & le & Negative & 419 \\
\hline 24 & 55 & UHC & le & I & \\
\hline
\end{tabular}

Abbreviations: HIV, human deficiency virus; IVDA, intravenous drug abuser; LDH, lactate dehydrogenase; N/D, not determined; NPHC, nonprotected homosexual contact; UHC, unprotected heterosexual contact.

The median CD4 T-cell count for the whole population at the time of neoplasm diagnosis was 100 cells/ $\mu \mathrm{L}$ with minor differences between the histopathologic subtypes; for patients with DLBCL, the median was 64 cells $/ \mu \mathrm{L}, 116$ cells $/ \mu \mathrm{L}$ in $\mathrm{BL}$, and 128 cells/ $\mu \mathrm{L}$ for those with PBL.

All diagnoses were confirmed by the histopathologic examination of excisional or punch biopsies. According to the histopathologic evaluation, the most common subtype was DLBCL (12 cases, 50\%), followed by PBL (9 cases, 37.5\%) and $\mathrm{BL}$ ( 3 cases, $12.5 \%)$.

HCV serologic status was available in 18 patients (75\%); 7 of them (38.9\%) were positive and were classified as coinfection (HIV/HCV). All patients with HCV infection were IVDA and one was hemophilic. The small size of this cohort represents a limitation to demonstrate any relation between coinfection with HCV and the risk to develop HN NHL.

In 9 patients, EBER determination was available; 7 cases were positive. In more than half (57.1\%) of EBER-positive patients, a diagnosis of DLBCL was confirmed. In addition, detection of HHV-8 RNA was performed in 10 patients with oral cavity involvement; 3 of them were positive. These results are summarized in - Table 3 .

\section{Discussion}

In the general population, extranodal NHL comprises 24 to $48 \%$ of all NHLs; approximately $10 \%$ of NHLs involve the HN region. ${ }^{6,7}$ Hodgkin lymphomas and NHLs can be seen in the HN region. Hodgkin lymphoma is most commonly located in the lymph nodes of the neck and mediastinum, and extranodal disease, with or without lymph node involvement, is more common among NHL. ${ }^{5}$ The majority of series including patients with AIDS-related lymphomas report a predominance of these neoplasms among men (75\% in our study) and in IVDAs ( $45.8 \%$ of our patients). ${ }^{8,9}$

The HN is the second most common site for extranodal lymphoma and can involve different areas such as Waldeyer ring (i.e., the tonsils, pharynx, and hypopharynx), salivary glands, orbit, paranasal sinuses, and thyroid glands. ${ }^{10}$ In the general population, Waldeyer ring has been reported as a common site of primary extranodal NHL of the HN with the tonsils as the most prevalent localization. ${ }^{11,12}$ Overall, 60 to $70 \%$ of head and neck NHLs occur in the Waldeyer ring and 10 to $20 \%$ of these arise from the nasopharynx, $, 6,9,13,14$ 
Table 2 Head and neck non-Hodgkin lymphoma localization $(n=24)$

\begin{tabular}{|c|c|c|c|c|c|c|c|}
\hline Patient no. & Skin and ST & Parotid gland & Cavum & Palate & Gingiva & Bone & Tonsils \\
\hline 1 & & Positive & & & & & \\
\hline 2 & & & Positive & & & & \\
\hline 3 & Positive & & & Positive & & & \\
\hline 4 & & & & & Positive & Positive & \\
\hline 5 & Positive & & & Positive & Positive & & \\
\hline 6 & & & & Positive & Positive & Positive & \\
\hline 7 & & & & Positive & Positive & & \\
\hline 8 & & Positive & & & & & \\
\hline 9 & & & & & & Positive & \\
\hline 10 & & & Positive & & & & \\
\hline 11 & Positive & & & & Positive & & \\
\hline 12 & & & & & Positive & & \\
\hline 13 & & & & & & & Positive \\
\hline 14 & & & & & Positive & & \\
\hline 15 & & Positive & & & & & \\
\hline 16 & & & & & Positive & & \\
\hline 17 & & & & & Positive & & Positive \\
\hline 18 & & & & & Positive & & \\
\hline 19 & Positive & & & Positive & Positive & & \\
\hline 20 & Positive & & & & & & \\
\hline 21 & & & & & Positive & Positive & \\
\hline 22 & & & & & & Positive & \\
\hline 23 & & & & Positive & Positive & Positive & \\
\hline 24 & & & & Positive & Positive & & \\
\hline
\end{tabular}

Abbreviation: ST, soft tissues.

NHL of the head and neck in patients with AIDS presents frequently as large local masses, with destruction of the maxilla, mandible, and bones around the paranasal sinus. ${ }^{15}$ When extending into the oral cavity, these large masses involving generally the gingiva and the hard palate frequently present as ulcerative lesions. ${ }^{3}$ In our series, which included only patients with AIDS, the oral cavity was the most frequent tissue involvement. Also, in the general population, NHLs rarely involve the salivary glands, which constitute $4 \%$ of these lymphomas. ${ }^{3,16}$ These tumors generally involve the parotid glands, as we could see in three patients of our series. $^{16-22}$ The majority of the patients in our series had $B$ symptoms as clinical presentation (fever, night sweats, and weight loss) similar to various opportunistic infections in this population; 17 patients $(70.8 \%$ ) were diagnosed in the early stage (I or II) of the neoplasm disease and 7 patients (29.1\%) had advanced stages (IV).

Even though all subtypes of NHL may be detected from the HN area, immunohistochemistry demonstrated that B-cell phenotype is predominant. ${ }^{23,24}$ Consistent with other studies, in our series, DLBCL was the most common histopathologic subtype and represented $50 \%$ of the patients, followed by the PBL with the $37.5 \%$ of subjects and BL with $12.5 \%$. WHO classifies PBL as an NHL of B-phenotype, predominantly occurring in HIV-seropositive patients. PBL was the second most common histopathologic subtype of HN NHL in our series. Also, PBL is an aggressive neoplasm, especially in immunosuppressed patients with HIV. ${ }^{3,16}$

As in the general population, LDH levels should be described as a prognostic factor in AIDS-associated NHL; $80 \%$ of the patients in this series had elevated levels of LDH. In our cohort, normal levels of $\mathrm{LDH}$ in the presentation were associated with no infiltration of bone marrow. These results may have therapeutic implications for future research, with the possibility of avoiding invasive procedures and reducing medical costs. However, the small size of the study group and the retrospective nature of the analysis are important limitations for a definitive conclusion. Future investigations in larger prospective cohorts may be useful to confirm these results.

In patients with AIDS, viral infections, especially EBV infection, have been associated with the pathogenesis of NHL. This association occurs with different frequencies depending on the clinical variant and the localization. HHV-8 is 
Table 3 Immunologic and histopathologic subtypes and virologic findings in 24 patients with head and neck non-Hodgkin lymphomas

\begin{tabular}{|l|l|l|l|l|l|}
\hline Patient no. & CD4 (cells/uL) & Type & EBV & HCV & HHV-8 \\
\hline 1 & 50 & DLBCL & Negative & Negative & N/D \\
\hline 2 & 177 & DLBCL & N/D & Positive & N/D \\
\hline 3 & 78 & BL & Positive & N/D & Negative \\
\hline 4 & 47 & DLBCL & Positive & N/D & N/D \\
\hline 5 & 30 & DLBCL & Positive & Negative & Negative \\
\hline 6 & DLBCL & Positive & N/D & Negative \\
\hline 7 & 189 & DLBCL & Positive & Positive & Negative \\
\hline 8 & 58 & DLBCL & N/D & Negative & N/D \\
\hline 9 & 305 & DLBCL & N/D & Negative & N/D \\
\hline 10 & 174 & DLBCL & N/D & Positive & N/D \\
\hline 11 & 19 & PBL & N/D & Negative & Negative \\
\hline 12 & 270 & BL & N/D & Negative & Negative \\
\hline 13 & 235 & DLBCL & N/D & Negative & Positive \\
\hline 14 & 173 & BL & N/D & Positive & N/D \\
\hline 15 & 116 & DLBCL & N/D & Negative & N/D \\
\hline 16 & 64 & PBL & Negative & Positive & Negative \\
\hline 17 & 85 & DLCL & N/D & N/D & N/D \\
\hline 18 & 49 & PBL & Positive & Negative & N/D \\
\hline 19 & 308 & PBL & N/D & N/D & N/D \\
\hline 20 & N/D & PBL & N/D & Negative & N/D \\
\hline 21 & 56 & PBL & Positive & N/D & N/D \\
\hline 22 & N/D & PBL & N/D & Positive & N/D \\
\hline 23 & 174 & PBL & N/D & Positive & Positive \\
\hline 24 & 57 & 215 & Negative & Positive \\
\hline
\end{tabular}

Abbreviations: BL, Burkitt lymphoma; DLBCL, diffuse large B-cell lymphoma; EBV, Epstein-Barr virus; HCV, hepatitis C virus; HHV-8, human herpesvirus8; N/D, not determined; PBL, plasmablastic lymphoma.

other oncogenic virus that has also been reported in association with lymphomas in patients with AIDS and HIV, especially in PBL. ${ }^{3,25,26}$ Also, HCV should have a role in the pathogenesis of lymphomas in patients coinfected with HIV. Duberg et al describe that patients infected with HCV have a high risk to develop NHL in comparison with general population. ${ }^{27}$ In our series, 7 of 18 patients (38.9\%) were infected by HCV probably related with the source of HIV infection.

There are obvious limitations to this study, including its retrospective nature and the absence of follow-up in the included cases. The small size of the cohort and the characteristics of a single center of infectious diseases should be included as another limitation to study the outcome after the diagnosis.

\section{Conclusion}

In this case series that includes only patients with HIV-AIDS disease, primary HN NHL was a frequent complication, arising more than $30 \%$ of all NHL. The majority of patients presented with early stage of this neoplasm disease, but with clinical manifestations (especially B symptoms) similar to some opportunistic infections that can affect this kind of patient. In contrast with the general population, in patients with AIDS, large intraoral cavity lesions, especially with the involvement of the hard palate and the gingival, were the most common clinical presentation. Early diagnosis (based on a high clinical suspicion) followed by combination therapy including highly active antiretroviral therapy plus chemotherapy can improve the poor prognosis of these patients.

\section{References}

1 Wolf T, Brodt H-R, Fichtlscherer S, et al. Changing incidence and prognostic factors of survival in AIDS-related non-Hodgkin's lymphoma in the era of highly active antiretroviral therapy (HAART). Leuk Lymphoma 2005;46(2):207-215

2 Tirelli U, Spina M, Gaidano G, Vaccher E, Franceschi S, Carbone A. Epidemiological, biological and clinical features of HIV-related 
lymphomas in the era of highly active antiretroviral therapy. AIDS 2000;14(12):1675-1688

3 Corti M, Villafañe MF, Solari R, et al. Non-Hodgkin lymphomas of the oral cavity in AIDS patients in a reference hospital of infectious diseases in Argentina: report of eleven cases and review of the literature. J Gastrointest Cancer 2011;42(3):143-148

4 Lymphoid neoplasms. In: Edge SB, Byrd DR, Compton CC, et al, eds. AJCC Cancer Staging Manual. 7th ed. New York, NY: Springer; 2010:599-628

5 Jaffe ES, Harris NL, Stein H, Vardiman JW; World Health Organization Classification of Tumors. Pathology and Genetics of Tumors of Haemopoietic and Lymphoid Tissues. Lyon, France: International Agency for Research on Cancer (IARC) Press; 2001

6 Laskar S, Mohindra P, Gupta S, Shet T, Muckaden MA. Non-Hodgkin lymphoma of the Waldeyer's ring: clinicopathologic and therapeutic issues. Leuk Lymphoma 2008;49(12):2263-2271

7 Weisenburger DD. Epidemiology of non-Hodgkin's lymphoma: recent findings regarding an emerging epidemic. Ann Oncol 1994;5(Suppl 1):19-24

8 Mohammadianpanah M, Omidvai S, Mosalei A, Ahmadloo N. Treatment results of tonsillar lymphoma: a 10-year experience. Ann Hematol 2005;84(4):223-226

9 Yong W, Zhang Y, Zheng W, Wei Y. Prognostic factors and therapeutic efficacy of combined radio-chemotherapy in Waldeyer's ring non-Hodgkin lymphoma. Chin Med J (Engl) 2000; 113(2):148-150

10 King AD, Lei KI, Richards PS, Ahuja AT. Non-Hodgkin's lymphoma of the nasopharynx: CT and MR imaging. Clin Radiol 2003;58(8): 621-625

11 Hashemi-Bahremani M, Parwaresch MR, Tabrizchi H, Gupta RK, Raffii MR. Lymphomas in Iran. Arch Iran Med 2007;10(3):343-348

12 Jacobs C, Hoppe RT. Non-Hodgkin's lymphomas of head and neck extranodal sites. Int J Radiat Oncol Biol Phys 1985;11(2):357-364

13 Devesa SS, Silverman DT, Young JL Jr, et al. Cancer incidence and mortality trends among whites in the United States, 1947-84. J Natl Cancer Inst 1987;79(4):701-770

14 Jacobs C, Weiss L, Hoppe RT. The management of extranodal head and neck lymphomas. Arch Otolaryngol Head Neck Surg 1986; 112(6):654-658
15 Weber AL, Rahemtullah A, Ferry JA. Hodgkin and non-Hodgkin lymphoma of the head and neck: clinical, pathologic, and imaging evaluation. Neuroimaging Clin N Am 2003;13(3):371-392

16 Dunn P, Kuo TT, Shih LY, et al. Primary salivary gland lymphoma: a clinicopathologic study of 23 cases in Taiwan. Acta Haematol 2004; 112(4):203-208

17 Kojima M, Shimizu K, Nishikawa M, et al. Primary salivary gland lymphoma among Japanese: a clinicopathological study of 30 cases. Leuk Lymphoma 2007;48(9):1793-1798

18 Kolokotronis A, Konstantinou N, Christakis I, et al. Localized B-cell non-Hodgkin's lymphoma of oral cavity and maxillofacial region: a clinical study. Oral Surg Oral Med Oral Pathol Oral Radiol Endod 2005;99(3):303-310

19 Morton LM, Turner JJ, Cerhan JR, et al. Proposed classification of lymphoid neoplasms for epidemiologic research from the pathology working group of the International Lymphoma Epidemiology Consortium (InterLymph). Blood 2007;110(2):695-708

20 Bunn BK, van Heerden WF. HIV/AIDS associated malignancies of the head and neck. SADJ 2012;67(10):590-592

21 Pazoki A, Jansisyanont P, Ord RA. Primary non-Hodgkin's lymphoma of the jaws: report of 4 cases and review of the literature. J Oral Maxillofac Surg 2003;61(1):112-117

22 Roh JL, Huh J, Suh C. Primary non-Hodgkin's lymphomas of the major salivary glands. J Surg Oncol 2008;97(1):35-39

23 Bajetta E, Buzzoni R, Rilke F, et al. Non-Hodgkin's lymphomas of Waldeyer's ring. Tumori 1983;69(2):129-136

24 Ye YL, Zhou MH, Lu XY, Dai YR, Wu WX. Nasopharyngeal and nasal malignant lymphoma: a clinicopathological study of 54 cases. Histopathology 1992;20(6):511-516

25 Corti M, Villafañe MF, Bistman A, Campitelli AM, Narbaitz M. Burkitt's lymphoma in AIDS patients: report of six patients and review of the literature. JSS 2013;2:198-202

26 Corti M, Soto I, Villafañe MF, Minué G, Campitelli A, Narbaitz M. Bone marrow necrosis as clinical presentation of plasmablastic lymphoma in an AIDS patient: first case reported and literature review. J Hematol Malig 2013;3:57-62

27 Duberg AS, Nordström M, Törner A, et al. Non-Hodgkin's lymphoma and other nonhepatic malignancies in Swedish patients with hepatitis C virus infection. Hepatology 2005;41(3):652-659 